\title{
DEVElopment STRATEgIES, SPECIALIZATION PATTERN AND GROWTH IN LATIN AMERICA
}

\author{
Pedro Clavijo and Jimmy Melo ${ }^{a}$
}

Fecha de recepción: 12 de febrero de 2020. Fecha de aceptación: 20 de agosto de 2020.

$$
\text { https://doi.org/10.22201/iiec.20078951e.2021.Especial.69576 }
$$

\begin{abstract}
This document determines the severity of the specialization pattern constraint on economic growth in Latin America for the period 1950-2016. For this purpose, Thirlwall's Law is estimated with the help of cointegration with structural break and time-varying parameter techniques. The results compel the conclusion that the specialization pattern has constrained economic growth in Latin America for the whole period, but the constraint has tightened severely during economic liberalization. Since results suggest that Latin America is stuck in a trap of falling-behind growth due to the specialization pattern, Thirlwall's Paradox is explored in a model that incorporates changes in productivity and reallocation of labor to analyze the conditions that allow investment to increase growth.
\end{abstract}

Key Words: development strategy; specialization pattern; economic growth; nonlinear cointegration; time-varying parameter; Thirlwall's Law.

\section{ESTRATEGIAS DE DESARROLLO, PATRÓN DE ESPECIALIZACIÓN Y CRECIMIENTO EN AMÉRICA LATINA}

Resumen. Este artículo determina la severidad del patrón de especialización que restringe el crecimiento económico en América Latina en el periodo 1950-2016. Para ello, se estima la Ley de Thirlwall con la ayuda de técnicas de cointegración con cambio estructural y parámetros variables en el tiempo. Los resultados llevan a concluir que el patrón de especialización ha restringido el crecimiento económico en América Latina durante todo el periodo, y la restricción se ha endurecido severamente durante la liberalización económica. Dado que los resultados sugieren que América Latina está atrapada en una trampa de crecimiento rezagado debido al patrón de especialización, la paradoja de Thirlwall se explora en un modelo que incorpora cambios en la productividad y reasignación de mano de obra para analizar las condiciones que permiten que la inversión aumente el crecimiento.

Palabras clave: estrategia de desarrollo; patrón de especialización; crecimiento económico; cointegración no lineal; parámetro variable en el tiempo; Ley de Thirlwall. Clasificación JEL: C14; F43; N16; O47.

a Universidad Católica de Colombia, Facultad de Ciencias Económicas y Administrativas and Universidad Central, Colombia. Email addresses: phclavijo@ucatolica.edu.co and jamelom@unal.edu.co, respectively. With the usual disclaimer, we want to thank Codrina Rada for her valuable comments on a previous draft of this document. 


\section{INTRODUCTION}

Despite a rich body of literature that highlights the importance of exporting high-value-added products to achieve high rates of growth, surprisingly, Latin America (LA hereafter) continues to export primary goods. Thus, LA continues to pile up decades of producing and exporting low-degree-of-complexity goods without noticing any exceptional change in growth or standard of living. Over the past three decades, after fostering Washington Consensus' liberal policies, LA's economic performance has been overwhelmingly disappointing and typified mostly by a specialization pattern that privileges the production of low-value-added products. This leads us to wonder whether the specialization pattern could be one of the suspects behind this disappointing economic performance.

The question of whether the specialization pattern is harmful to LA's growth has been previously researched with results that emphasize a negative relation between growth and a primary specialization pattern (see, e.g., Sachs and Warner, 1997, 1999; Chami, 2004). The question, however, has not been examined in the context of specific development strategies, ${ }^{1}$ and therefore, it is not clear whether liberal policies could explain the protracted LA's economic malaise. Hence, this previous literature needs to be complemented by additional evidence to study the impact of alternative development strategies on long term growth. It, therefore, becomes enlightening, and indeed essential, to identify the magnitude of those constraints and suggest measures to prevent their emergence. In that sense, the primary aim of this document is to assess the severity of the specialization pattern constraint on LA's economic growth throughout its development strategies.

The period covered by this document includes the import substitution industrialization (ISI) (1950-1980) and economic liberalization strategies (1981-2016). The former, conceived industrialization as an instrument to revamp manufacturing industries and thus modify the specialization pattern. The latter, in contrast, neglects specialization pattern as a constraint on growth, and therefore, industrialization is not a priority. The priority is merely to allow the price mechanism to allocate resources in those sectors where countries have static comparative advantages. Any interference, such as in-

1 A development strategy is a set of policies designed to forge a productive structure that yields high and stable economic growth rates to achieve an aim of convergence with the income level in developed countries. 
dustrial policies, only distorts price signals, reduces efficiency, and obstructs international trade gains.

The drawback, however, is that the price mechanism may create a specialization pattern that yields the lowest long-term economic benefits. Ros (2001) suggests that those low economic benefits often result because a country's static comparative advantages differ from its dynamic comparative advantages. Industrialization, therefore, becomes essential since it allows for the creation of dynamic comparative advantages that promotes technological innovation, generates learning by doing, raises productivity, and draws labor from less productive sectors. In this sense, a specialization pattern based on dynamic comparative advantages may create a more sophisticated export basket that yields the greatest economic benefits in the long term.

Empirical evidence suggests that developing highly competitive manufacturing industries with a significant share in manufactured goods export markets fosters growth (Ferreira and De Santana, 2019). Hausmann et al. (2007) find that rich countries differentiate from poor ones because they produce more sophisticated goods with higher productivity levels, while, for their part, poor countries produce backward goods on the productivity scale. Those findings deliver a consistent message: producing potato chips or computer chips has important implications for economic growth since specializing in some products will bring higher growth than specializing in others. Not all sectors have the same ability to inject dynamism into the economy or to propagate technical progress.

Economies specializing in the production and export of primary goods tend to grow more slowly than those specializing in the export of manufactured goods (Sachs and Warner, 1997; Sala-i-Martin, 1997). Sachs and Warner (1997), with cross-country data, show the negative association between resource abundance and growth. An increase of one standard deviation of the natural resource export variable was associated with a reduction in annual average growth of $0.39 \%$. Over a 20 -year period, this effect would reduce percapita Gross Domestic Product (GDP) by about 7\%. Later, Sachs and Warner (1999) used a time series analysis to complement their previous findings by showing that natural resource booms have not only done little to generate long term growth but indeed have hindered growth on the average.

In general, the empirical evidence and the poor economic performance of LA under liberalization suggest that the specialization pattern, and with it, the position LA adopts into the international division of labor, have stunted the development in the region. Interestingly, the liberal strategy attained the aim of boosting the export sector in LA, although, as it is shown in this docu- 
ment, the exporting dynamism has hampered economic growth. To a large extent, this can be explained by the surge of imports that the region experienced after liberalization.

Now, the theoretical framework we invoke to analyze the specialization pattern effects on growth is the balance-of-payments-constrained growth model developed initially by Thirlwall (1979) known as Thirlwall's Law. Thirlwall's model links growth and trade through the specialization pattern defined as the ratio of income elasticities of demand for exports and imports. Within this framework, Pacheco-López and Thirlwall (2006) test for LA Thirlwall's Law to determine whether a growth decrease can be discerned as a result of an increase in the income elasticity of demand for imports after trade liberalization. With the help of rolling regression, they find a trend increase in the income elasticity of demand for imports after liberalization.

In the same vein of the balance-of-payments-constrained growth model, Cimoli et al. (2010) also find that the income elasticity of demand for imports in LA shows an upward trend, particularly after the mid-1970s. They argue that LA failed to converge with the developed world since 1960 because the upward trend in imports was not matched by a similar increase in exports. Guerrero (2006) applies Thirlwall's Law to nineteen Latin American countries using a stochastic specification of the Law to focus on the ratio of export/ import income elasticities. On average, he finds a diminishing ratio of income elasticities, which represents an unexpected result considering liberal reforms have put all the effort in promoting exports.

To date, there has been a paucity of studies applying the balance-of-payments-constrained growth model to LA. In this document, we contribute to this literature motivated by some aspects not treated in previous studies. In general, none of the previous studies consider potential structural breaks in the model even though parameters of econometric models are dependent on current policy and will react to policy changes. What Pacheco-López and Thirlwall (2006) rolling regression approach reveals is an inherent parameter instability that requires a more sophisticated technique that allows the estimated parameter to be time-dependent.

Guerrero (2006) addresses this issue by employing a time-dependent parameter specification of the model. The drawback, however, is that he applies the model to single countries, such as El Salvador, and Thirlwall's Law applies for large economies. In the case of small economies (such as El Salvador), the Law breaks down, and the external growth rate is no longer a country's growth rate determinant (for a discussion on the matter see, Clavijo and Ros, 2015; Ibarra, 2015; Pérez, 2015; Vernengo, 2015; Ros and Clavijo, 
2015; Razmi, 2016). Hence, we follow Pacheco-López and Thirlwall (2006), and Cimoli et al. (2010) in conceiving LA as a unit to guarantee we are dealing with a large economy. ${ }^{2}$

However, taking the case of a large economy (an economy whose growth affects its terms of trade) entails coping with what Ros (2013) called Thirlwall's Paradox. The Paradox states that investment is incapable of sustaining a development process because of the terms of trade deterioration it generates. The result is paradoxical since capital accumulation has been considered typically as an engine of development, but in Thirlwall's model, it has no effect. Furthermore, it is paradoxical because the policy content within the literature on the balance-of-payments-constrained growth model rests typically on enhancing capital accumulation to overcome the constraint even though it is not clear how to overcome the Paradox (see, Perrotini and Vázquez, 2019).

In this document, we present a simple model that analyzes under what conditions the Paradox breaks down so investment could sustain a development process. To our knowledge, the Paradox has not been addressed before. In this sense, this document not only contributes to the empirical literature by considering aspects neglected in previous works but also helps to bridge this gap in the theoretical literature by proposing a potentially extensible model to cope with an overlooked criticism.

The document proceeds as follows. Section 2 presents Thirlwall's Law within a North-South trade model à la Dutt (2002). Section 3 introduces the econometric technique of cointegration with a structural break and the time-varying parameters model we follow to test the hypothesis of growth constrained by specialization pattern in LA for the period 1950-2016. In the section 4, we present an extension of the balance-of-payments-constrained growth model that copes with Thirlwall's Paradox. The last section concludes that economic liberalization has led LA toward a low growth equilibrium.

\section{THIRLWALL'S LAW AND THE CASE OF A LARGE ECONOMY}

In general terms, the study of development in developing economies requires studying the interactions between these economies and advanced countries (Akamatsu, 1962). Ever since Prebisch wrote in 1950 the Latin American

2 The case of countries would require testing first the assumption of a large economy. A block of countries like LA makes it easier to sustain the assumption. 
Manifesto, there has been an increasing interest in the study of economic interaction between LA and the developed world. In this sense, the heirs of the structuralist theory have emphasized asymmetric interactions between these two regions integrating the theory of trade with growth theory to explain the uneven distribution of international trade gains (see, e.g., Cimoli and Porcile, 2014).

The interaction between developing and developed countries have been widely analyzed within the framework of North-South trade models since they allow for highlighting structural asymmetries between both regions (see Taylor, 1983 for pioneering work on the matter). Nevertheless, the versatility of this type of models also allows documenting the outcomes of the interaction between developing countries with different degrees of development (see Ros, 2012).

This document follows the structuralist tradition and presents a NorthSouth trade model whose core is Thirlwall's Law to capture the effects on LA's growth rate of the interaction between LA and advanced economies. We believe that, to a significant extent, the model depicts the main structural asymmetries between the regions. Thirlwall's Law has previously been analyzed in the context of North-South trade models (see, e.g., Dutt, 2002; Vera, 2006; Sasaki, 2008). Indeed, the model draws heavily on Dutt (2002), although with variations and extensions. We find Dutt's Thirlwall model representation appealing since it explicitly presents how output level changes, how output is produced, relations between production and distribution, and what the accumulation rhythm is.

To start with, consider the existence of two regions, LA and developed world (Dw hereafter), which interact through international trade in a complementary but unequal manner. DW has a homogeneous productive apparatus that allows it to produce a good $\left(Y_{D W}\right)$ under even levels of productivity. For its part, LA presents a heterogeneous productive structure and produces one good $\left(Y_{L A}\right)$ with significant differences in productivity among sectors. The modern sector is considered to be the most prone to technological change, and it is exposed to international markets. For its part, the subsistence sector presents no opportunities for technological progress, and it is mainly inwardoriented. Thus, the model presents a marginalized sector around which gravitate most of LA's problems of underemployment and low incomes. 


\section{Latin America}

Suppose the modern $(M)$ sector's production technology exhibits constant returns to scale. Assume, for simplicity, that $Y_{M}=K_{M}^{\alpha}\left(A L_{M}\right)^{1-\alpha}$ where $Y_{M}$, $L_{M}$ and $K_{M}$ are output, employment, and capital stock, respectively. Modern sector's employment is determined by the usual profit maximization conditions such that $L_{M}=\left[\frac{(1-\alpha) A^{1-\alpha}}{\omega_{M}}\right]^{1 / \alpha} K_{M}$ where $\omega_{M}$ is the real wage in this sector. By plugging $L_{M}$ into $Y_{M}$ the output level can be expressed as a function of the capital stock:

$Y_{M}=\rho K_{M}$

where $\rho=\left[\frac{(1-\alpha) A}{\omega_{M}}\right]^{1-\alpha / \alpha}$ represents capital productivity.

Latin American structuralism has always been concerned with the heterogeneity of LA's economic apparatus, where sectors with different levels of productivity coexist within the economy. Modern and subsistence sectors coexist because, in the latter, a significant share of the labor force remains in a state of disguised unemployment that represents a perfectly elastic supply of labor for the modern sector. It is essential to bear in mind that a dualistic economy not necessarily captures the concept of structural heterogeneity; however, for simplicity's sake, both theories are considered as close substitutes.

Regarding subsistence sector $(S)$, technology displays constant returns to labor, and output $\left(Y_{S}\right)$ is given by: $Y_{S}=L_{S}$ where $L_{S}$ is the employment level. Since the production process involves no capital, the subsistence sector is forced to employ more primitive modes of production. Wages in the modern sector are completely spent in consumption of the modern good according to $\omega_{M} b_{M} Y_{M}$ where $b_{M}$ is the labor required per unit of good produced. As for subsistence sector output, it is consumed internally. Additionally, profits are entirely used to acquire the investment good produced in DW. Excess production over internal consumption of the modern good is exported to DW. Therefore, LA's market-clearing macroeconomic condition can be formulated as $Y_{M}+Y_{S}=\omega_{M} b_{M} Y_{M}+Y_{S}+X$ or:

$X=Y_{M}\left(1-\omega_{M} b_{M}\right)$ 
where $X$ stands for the exports from LA to Dw. Plugging (1) into (2) yields,

$$
X=\rho \Pi K_{M}
$$

with $\Pi=\left(1-\omega_{M} b_{M}\right)$ as modern sector's profits. Note that LA's exports are an increasing function on the capital stock, which, to some extent, represents LA's capacity to produce the exportable good. In this sense, export capacity can shrink due to a lack of productive potential (measured by $K_{M}$ ), all else equal.

Prices are flexible and respond to excess demand (or supply). In this manner, market clearing is achieved instantaneously by changes in price $\left(P_{L A}\right)$. Now, to keep this model comparable with others following Thirlwall's original work on balance-of-payments-constrained growth, additional components of the balance of payments such as capital flows are omitted. Thus, the balance of payments equilibrium is equal to the trade balance. If $M$ represents LA's imports, the equilibrium of the balance of payments is:

$$
M=P X
$$

$$
\text { where } P=P_{L A} / P_{D W} \text { stands for LA's terms of trade. }
$$

Equation (4) suggests that LA's import capacity fundamentally depends on export volume as well as on the terms of trade. Therefore, if LA must maintain its balance of payments in equilibrium, the sustainable manner of improving its import capacity is by improving its export capacity, which according to (3), hinges on capital accumulation.

\section{The developed world}

Prebisch (1950) noted that an obstacle for development in LA was the dramatic difference with developed countries regarding institutions and economic conditions. Those differences guaranteed that developed countries would keep their gains in productivity since, for example, in those countries, wages were rigidly moving downward due to unions' bargaining leverage. Furthermore, Prebisch pointed out that imperfect competition in developed markets conferred firms the ability to set prices and rigidly maintain their profit share.

In that regard, assume firms in DW set prices according to a mark-up equation: $P_{D W}=(1+\tau) W_{D W} b_{D W} . \tau$ is the mark-up exogenously determined and represents the degree of monopoly; $W_{D W}$ stands for the nominal wage in DW 
assumed constant in this case due to negotiations between firms and workers; and $b_{D W}$ is the labor required per unit of production. In Dw, capitalists save a fraction $s_{D W}$ of their income, and workers spend their entire income in consumption.

Capitalists, as well as workers, spend a fraction $\alpha$ of their income in consuming the Latin good, and the rest is allocated to consume the local good; DW exhibits a more diversified consumption pattern compared with LA as a result of the higher degree of development. The fraction $\alpha$ is determined by the following expression: $\alpha=\alpha_{0} Y_{D W}^{\varepsilon_{D W}-1} P^{1-\mu_{D W}}$ where $\varepsilon$ is the income elasticity; $\mu$ is the absolute value of the price elasticity; and $\alpha_{0}$ is a constant. Now, the expression for the value of DW imports is given by: $P_{L A} X=\alpha\left\{\frac{\left[1+\left(1-s_{D W}\right) \tau\right]}{1+\tau}\right\} P_{D W} Y_{D W}$. Plugging $\alpha$, yields Dw demand function for the Latin good:

$$
\begin{aligned}
& X=\phi P^{-\mu_{D W}} Y_{D W}^{\varepsilon_{D W}} \\
& \text { with } \varphi=\alpha_{0} \frac{\left[1+\left(1-s_{D W}\right) \tau\right]}{1+\tau} .
\end{aligned}
$$

\section{Short-term equilibrium}

In DW, income is employed to consume $\left(C_{D W}\right)$, invest $\left(I_{D W}\right)$ and import $\left(M_{D W}\right)$. Therefore, $Z_{D W}$, which represents the uses of income, is equal to: $Z_{D W}=C_{D W}+I_{D W}+M_{D W}$. Assume the investment function is $I_{D W}=\sigma_{0} K_{D W}+\sigma_{1} Y_{D W}$, with $\sigma_{0}$ and $\sigma_{1}$ measuring the sensitivity of investment respect to capital stock and income, respectively. On the other hand, the sources of income, $Y_{D W}$, are consumption, savings $\left(S_{D W}\right)$, and exports to LA $\left(X_{D W}\right)$. Thus, $Y_{D W}=C_{D W}+S_{D W}+X_{D W}$, where savings are equal to: $S_{D W}=s_{D W} \delta Y_{D W}$, with $\delta=\tau / 1+\tau$ as the profit share.

In the short-term, when the capital stock remains constant, the macroeconomic equilibrium condition in DW entails $Y_{D W}=Z_{D W}$. Equaling expressions and performing the substitutions required, the DW output level is given by:

$$
Y_{D W}=\kappa K_{D W}
$$

$$
\text { where } \kappa=\frac{\sigma_{0}}{\left(s_{D W} \delta-\sigma_{1}\right)} \text {. }
$$


As for LA, the short-term equilibrium requires balanced trade (as well as in DW), given the capital stock. Equations (3), (5), and (6) yield the value of the terms of trade that guarantees LA short-term equilibrium:

$$
P=\left[\frac{\phi\left(\kappa K_{D W}\right)^{\varepsilon} D W}{\rho \Pi K_{M}}\right]^{1 / \mu_{D W}}
$$

\section{The medium-term equilibrium}

In the medium-term, the capital stock in both regions grows according to the accumulation rate given by $g_{i}=\frac{I_{i}}{K_{i}}$. Assuming no depreciation of the capital stock, the accumulation rate in DW is: $g_{D W}=\frac{I_{D W}}{K_{D W}}=\sigma_{0}+\sigma_{1} \frac{Y_{D W}}{K_{D W}}$. Plugging (6) yields:

$$
g_{D W}=\sigma_{0}+\sigma_{1} \kappa
$$

In LA, the capital accumulation rate equals the capital accumulation rate in the modern sector: $g_{L A}=\frac{I_{M}}{K_{M}}$. Since Latin imports consist of the investment good produced in DW, investment equals the purchases LA makes of DW good: $I_{M}=M$. Hence, employing equations (3) and (4), it can be shown that LA accumulation rate is a function of the terms of trade given by:

$$
g_{L A}=\rho \Pi P
$$

The dynamic expression of (7) yields the growth rate of the terms of trade:

$$
\hat{P}=\frac{1}{\mu_{D W}}\left(\varepsilon_{D W} g_{D W}-g_{L A}\right)
$$

Equation (10) implies that the dynamic behavior of the terms of trade depends on the gap between $g_{L A}$ and $\varepsilon_{D W} g_{D W}$. Now, the medium-term equilibrium condition requires terms of trade to be stationary over time, this means, $\widehat{P}=0$. Imposing this condition on (10), LA's output growth rate is:

$$
g_{L A}=\varepsilon_{D W} g_{D W}
$$


Suppose $\varepsilon_{D W}<1$. The assumption means LA specializes in producing income-inelastic goods while DW specializes in goods with unitary income elasticity, and therefore, larger. Consequently, in figure 1 , the line $\varepsilon_{D W} g_{D W}$ lies below the line $g_{D W}$ and the intersection of lines $g_{L A}$ and $\varepsilon_{D W} g_{D W}$ indicates the medium-term equilibrium where terms of trade, as well as accumulation rates, are stationary. A more general expression of equation (11A) where LA's income elasticity is different from the unity can be formulated as:

$$
g_{L A}=\frac{\varepsilon_{D W}}{\varepsilon_{L A}} g_{D W}
$$

Equation (11B), known in the literature as Thirlwall's Law, states that Dw's growth rate, as well as the ratio of income elasticities of demand, determine LA's growth rate (or capital accumulation in this model). By taking the dynamic expression of (5) and using the steady-state condition of the terms of trade, it is straightforward to show that exports growth rate equals $\varepsilon_{D W} g_{D W}$. Thus, an alternative interpretation of the Law states that in the medium run, LA grows constrained by exports growth rate, divided by the income elasticity of demand for imports.

Let us now analyze the equilibrium conditions. Imagine the economy starts from an initial situation where $P>P^{*}$ and therefore $g_{L A}>\varepsilon_{D W} g_{D W}$. Thus, LA's demand for imports grows faster than the demand for its exports, because LA produces income-inelastic goods; hence, according to the equation (10), terms of trade deteriorate over time to reestablish the balance of payment equilibrium in LA. The deterioration in relative prices discourages the accumulation of capital in LA, and the accumulation rate returns to the point where $g_{L A}=\varepsilon_{D W} g_{D W}$ with stationary terms of trade. The opposed analysis is true for any $P<P^{*}$.

Note that the specialization pattern (the ratio of elasticities) determines the position of the medium-term equilibrium in the steady state, entirely. Therefore, the implications of assuming $\varepsilon_{D W}<1$ are dramatic: if LA exports primary goods or basic manufactures of low-income elasticity of demand, and imports industrial products of high-income elasticity of demand, the equation (11B) predicts that LA must grow at a slower rate than DW grows in order to maintain its balance of payments in equilibrium. 
Pedro Clavijo and Jimmy Melo

Figure 1. Medium-term equilibrium determination

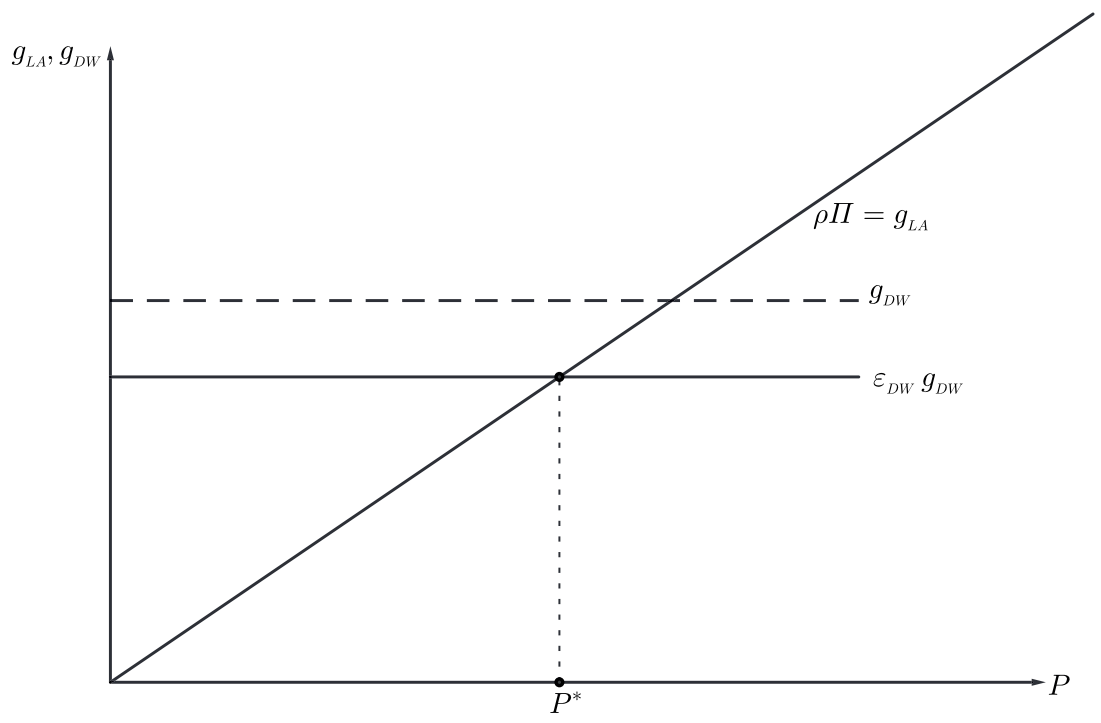

Source: own elaboration.

Consequently, exports are crucial for growth: if $\varepsilon_{D W}<\varepsilon_{L A}$ LA will be forced to export all its gains in productivity at a consistently higher rate to support its import requirements and thus maintain trade equilibrium. To a considerable extent, the depletion of ISI was a consequence of the incapacity of the strategy to reverse the latter inequality and halt the productivity drain.

\section{EMPIRICS}

This section aims to test the central hypothesis underpinning Thirlwall's Law, which states that specialization pattern is the primary constraint on growth in the medium run. To test it, we use a cointegration technique allowing for a structural break and a time-varying parameter model to estimate the econometric version of equation (11B). 


\section{Data}

We gather annual data for LA and DW ${ }^{3}$ GDP in 2011 dollars (Purchasing Power Parity (PPP) corrected) from the Maddison Project Database (Inklaar et al., 2018) over the period 1950-2016. ${ }^{4}$ Following Cimoli et al. (2010), the DW includes mature industrial economies whose exports consist mainly of industrial goods along with economies in which natural resources still account for a relevant part of the total exports. Additionally, some rich countries are included (not necessarily developed, such as Saudi Arabia) since they influence the price of some essential primary goods LA exports. ${ }^{5}$ Figure 2 presents the trajectory of the log transformation of real GDP for both regions over the sample period. There seems to be a close comovement or cointegration between the series, although that association may have altered over time. The shadowed portion of the graph separates the two development strategies. We select 1981 because the 80 s ("The lost decade") represents the transition period between ISI and economic liberalization but also because the behavior of LA GDP seems to have changed its trajectory after this year.

The protracted rise of the GDP during the ISI era (1950-1980) contrasts with the flatter pace of the GDP under the economic liberalization age (19812016). Accompanied by ISI, LA grew at an average annual rate of about $5.5 \%$, while under liberalization, the growth rate has plunged by nearly $3.1 \%$. Below we show that our econometric approach accurately captures this marked change in LA's GDP behavior.

LA: Argentina, Bolivia, Brazil, Barbados, Chile, Colombia, Costa Rica, Cuba, Dominica, Dominican Republic, Ecuador, Guatemala, Honduras, Haiti, Jamaica, Saint Lucia, Mexico, Nicaragua, Panama, Peru, Puerto Rico, Paraguay, Salvador, Trinidad and Tobago, Uruguay, Venezuela. Dw: Australia, Austria, Belgium, Canada, Switzerland, Cyprus, Germany, Denmark, Spain, Finland, France, United Kingdom, Greece, Ireland, Iceland, Italy, Luxembourg, Malta, Netherlands, Norway, New Zealand, Portugal, Sweden, United States, China, Hong Kong, India, Japan, Republic of Korea, Saudi Arabia, Singapore, Taiwan.

4 Refer to <www.ggdc.net/maddison for documentation and explanation of the data series>

5 Clearly, other combinations of countries could have been formed. 
Figure 2. Log of real GDP of LA and DW, 1950-2016

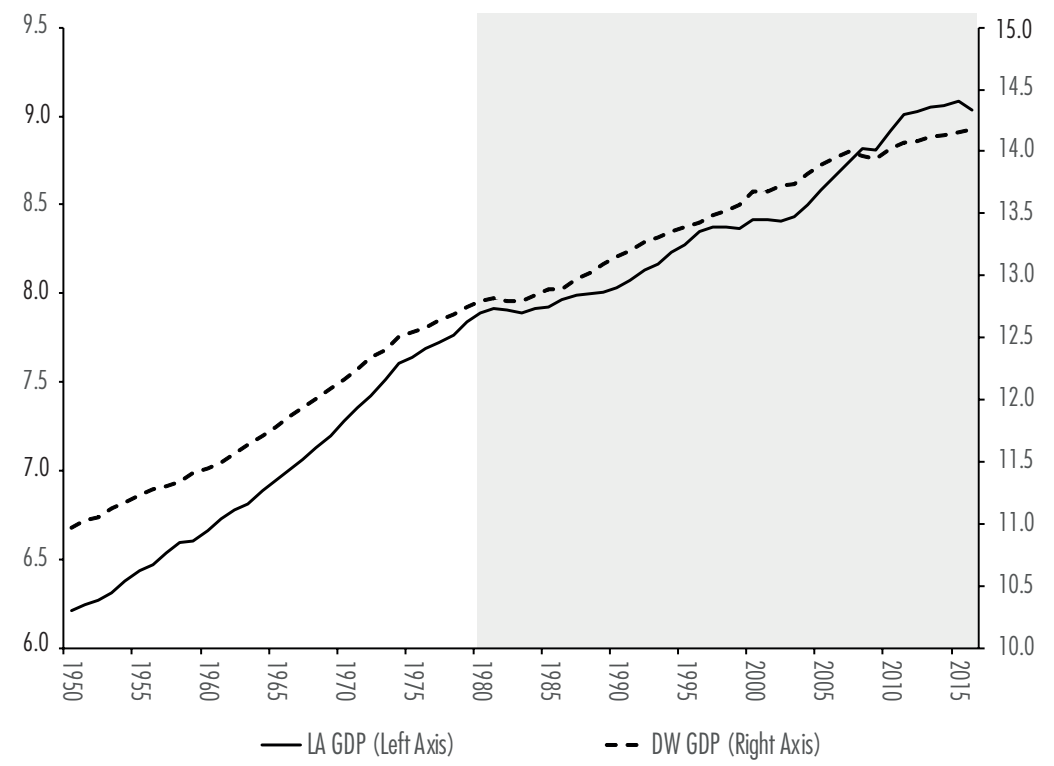

Source: own elaboration based on information from the Maddison Project Database.

\section{The cointegration model}

Table 1 shows the results of $\mathrm{Ng}$ and Perron's (2001) unit root test for the logarithm of the real GDP. Ng-Perron test uses the GLS detrending procedure to create efficient versions of the modified Phillips (1987) test (Mza), Phillips and Perron (1988) (Mzt), Bhargava (1986) (MSB), and the Point Optimal Test by Elliott, Rothenberg and Stock (1996) (МРT). The modification is done by combining a Modified Information Criterion for the lag length and a Generalized Least Squares method for detrending the data.

As noted from figure 2, the GDP series seems to have a deterministic trend according to what macroeconomic theory suggests (see, Elder and Kennedy, 2001). Hence, we perform the unit root test with an intercept and a trend as deterministic components in the regression. Based on the results and inference of the 5\% level of significance, we cannot reject the null hypothesis of a unit root. It is well known, however, that one disadvantage of the standard unit root tests is the implicit assumption that the deterministic trend of the series is correctly specified. Structural breaks in the mean of a stationary time series bias the usual test for a unit root toward non-rejection (Perron, 1989). 
Table 1 presents the results of the unit root test developed by Lee and Strazicich (2013). The test contrasts the null hypothesis of a unit root with a structural break, against the alternative of stationarity with a structural break. Ls(См) and Ls(твм) report the unit root test for the crash and breaking trend, respectively. The null of unit root cannot be rejected, even allowing for breaks. Both variables are stationary in first differences.

After the presence of a unit root has been verified, the next step entails testing whether there is a stable relationship between these variables through time. To test for potential linear cointegration, we employ Johansen's test. Table 2 presents the results of Johansen's cointegration test, where a time trend has been included in the cointegrating regression as in the unit root test. The results suggest no cointegration between the variables since we cannot reject the null hypothesis of no cointegration with the trace and maximum-eigenvalue tests at a $5 \%$ level of significance.

Table 1. Unit root tests

\begin{tabular}{lcccc}
\hline Tests & $L A$ & $D W$ & $\Delta L A$ & $\Delta D W$ \\
\hline MZA $^{\text {GLS }}$ & -4.98 & -0.26 & $-26.25^{\star *}$ & $-31.55^{\star \star}$ \\
MZT $^{\text {GLS }}$ & -1.48 & -0.13 & $-3.43^{\star \star}$ & $-3.96^{\star \star}$ \\
MSB $^{\text {GLS }}$ & 0.30 & 0.47 & $0.13^{\star \star}$ & $0.13^{\star \star}$ \\
MPT $^{\text {GLS }}$ & 17.78 & 53.66 & $4.58^{\star \star}$ & $2.95^{\star \star}$ \\
LS(CM) & -2.37 & -2.67 & & \\
LS(TBM) & -6.29 & -5.21 & & \\
\hline
\end{tabular}

Note: ${ }^{\star \star}$ significance at $5 \%$ levels.

Source: own elaboration.

Table 2. Johansen's cointegration test for a VAR(2)

\begin{tabular}{cccccccc}
\hline \multicolumn{3}{c}{ Trace } & \multicolumn{5}{c}{$\lambda \max$} \\
\hline HO & $H 1$ & Statistics & C.V. 5\% & HO & $H I$ & Statistics & C.V. $5 \%$ \\
$r=0$ & $r \geqslant 1$ & 11.49 & 25.87 & $r=0$ & $r=1$ & 8.62 & 19.39 \\
$r \leqslant 1$ & $r \geqslant 2$ & 2.87 & 12.52 & $r \leqslant 1$ & $r=2$ & 2.87 & 12.52 \\
\hline
\end{tabular}

Note: we use Akaike's information criterion to select VAR's order. The VAR residual serial correlation LM test (HO no serial correlation at lag order $h): h=1[5.75] ; h=2[2.37] ; h=3[4.26]$. The LM-stat in square brackets implies there is no serial correlation up to lag 3.

Source: own elaboration. 
The null hypothesis of no cointegration cannot be rejected because, for instance, the presence of a structural break in the cointegrating equation. Gregory et al. (1996) carefully illustrate the challenges of standard tests for cointegration in the presence of a structural break. They show that ignoring the existence of a structural breakpoint in a long-run relationship between a set of non-stationary variables lessens the power of regular tests of cointegration and biases the test in favor of non-rejection of the null hypothesis of no cointegration.

Since parameter instability is a common phenomenon in time series analysis, it is essential to bear in mind that a structural break is a possibility. In the context of the present document, it seems reasonable to expect a break in the cointegrating equation since the sample includes the transition from ISI to economic liberalization. Hence, the next step is to test for breaks in the medium-run relationship between LA and DW GDP with the help of Carrion-iSilvestre and Sansós (2006) test.

Carrion-i-Silvestre and Sansós test is especially useful in situations where we are interested in modeling a cointegrating relationship that, at a point in time, might have shifted from a medium-run path to another. An additional advantage of this model is that it tests for the more natural null hypothesis of cointegration. Specifically, the model compares the null hypothesis of cointegration with a structural break with the alternative of no cointegration. Following Carrion-i-Silvestre and Sansó, the data generating process can be written as:

$$
g d p_{L A, t}=o_{t}+\zeta t+\beta_{1} g d p_{D W, t}+\omega_{t}
$$

where $g d p_{L A, t}$ and $g d p_{D W, t}$ are log transformations of the real GDP of LA and the real GDP of DW, respectively; $\beta_{1}=\frac{\varepsilon_{D W}}{\varepsilon_{L A}} ; t$ represents a time trend; $\omega_{t}$ stands for an error term; $o_{t}=f(t)+o_{t-1}+\eta_{t}, f(t)$ describes the break; and $\eta_{t} \sim \operatorname{iid}\left(0, \sigma_{\eta}^{2}\right)$.

In contrast to regular tests, Carrion-i-Silvestre and Sansós test provides a comprehensive treatment of issues related to testing cointegration with a structural break where breaks can occur in both the deterministic and the cointegration vectors. Since we are interested in assessing whether LA has shifted from one medium-run equilibrium to another under the liberal era we estimate Carrion-i-Silvestre and Sansó's model $\mathrm{E}$ (the regime shift model) where $\zeta \neq 0$, and $f(t)=\theta D\left(T_{b}\right)_{t}+\varphi D U_{t}+\beta_{2} g d p_{D W, t} D\left(T_{b}\right)_{t}$ with $D\left(T_{b}\right)_{t}$ as a dummy variable indicating the break at a point of time $T_{b}$, and $D U_{t}$ as a dummy variable equals 1 if $t>T_{b}$ and 0 otherwise. 
Thus, we have opted for a specification for Carrion-i-Silvestre and Sansó's test that contemplates a time trend and allows for a single structural break in the intercept, trend, and cointegrating coefficient, at an unknown point in time with an endogenous regressor.

Table 3. Carrion-i-Silvestre and Sansó's cointegration test with one break in deterministic and the cointegration vectors (regime change)

\begin{tabular}{ccc}
\hline \multicolumn{3}{c}{ Model $E$ under the null of cointegation: } \\
$g d p_{L A, t}=o+\zeta t+\beta_{1} g d p_{D W, t}+\beta_{2} g d p_{D W, t} D U_{t}+\theta D U_{t}+\varphi D T_{t}^{*}+\omega_{t}$ \\
\hline Break Year & Test statistic (SC) & C.V. $5 \%$ \\
1984 & 0.0361 & 0.0512 \\
\hline
\end{tabular}

Source: own elaboration.

The null hypothesis of cointegration with a structural break is rejected if the test statistic exceeds its critical value. Therefore, based on the estimated break date, we cannot reject the null hypothesis that there is a cointegrating relationship with a break using a 5\% significance level.

The most remarkable result from Carrion-i-Silvestre and Sansós cointegration test is the break date detected by the mid-80s precisely during the "lost decade". It is common knowledge that in the 1980s, the Latin American debt crisis placed the region in a difficult situation after developed countries tightened the monetary policy leading to a general contraction of credit. This liquidity squeeze created an advantageous scenario for the International Monetary Fund, along with the World Bank, to start their campaign for structural reforms in LA. The structural adjustment programs were forged during the "lost decade", which later in the nineties, reshaped Latin American economies according to pro-market principles. In this sense, the cointegration model accurately captures the transition from IsI toward economic liberalism in LA.

\section{The time-varying coefficients model}

How to cope with structural breaks is a rich topic in econometric theory that has received considerable attention in recent times (see, e.g., Kreinovich and Sriboonchitta, 2019). One way to address the issue of a structural break in the cointegrating equation is by using a time-varying coefficients model em- 
ploying a state space representation. Guerrero (2006) used the same approach in his estimation of Thirlwall's Law. We follow Guerrero in using these timevarying parameters approach that has not yet been exploited to the fullest in this literature.

The state space model consists of two equations: the state equation and the space equation. The state equation describes the dynamics of the state variables while the space equation relates the observed variables and the unobserved state variables. The following systems of equations give Thirlwall's Law state space representation:

$$
\begin{aligned}
& g d p_{L A, t}=\beta_{t} g d p_{D W, t}+u_{t} \\
& \beta_{t+1}=\varrho_{0}+\varrho_{1} \beta_{t}+\epsilon_{t+1}
\end{aligned}
$$

The interest lies in analyzing the medium-term multiplier of $g d p_{L A}$ respect to $g d p_{D W}$. The multiplier represents the medium-term ratio of income elasticities of demand for exports and imports according to equation (11B). The two possible scenarios of interest are $\frac{\varepsilon_{D W}}{\varepsilon_{L A}}<1$ and $\frac{\varepsilon_{D W}}{\varepsilon_{L A}} \geq 1$. While the former indicates a divergent growth pattern, the latter indicates a convergent growth pattern, both attributable to the specialization pattern, as defined by Thirlwall.

It is also possible that other variables affect the real GDP of LA, however, we ignore these other variables since the focus is on analyzing the medium-run relationship between LA and DW considering the theoretical model proposed. ${ }^{6}$ Figure 3 illustrates the evolution of the maximum likelihood estimates of $\beta_{t}$ using the BFGS optimization technique.

Parameter instability over time is evident in figure 3. While the mediumrun ratio of income elasticities of demand for exports and imports for the pre-break period presents an upward slope, the post-break ratio is downward sloping. Interestingly, the post-break ratio also presents an upswing around 2005. The upswing is associated with a significant upward shift in primary commodity prices since 2005. According to Geronimi and Taranco (2018), such an upward shift represents an unprecedented rise in primary terms of trade of $57.5 \%$, which led Latin American countries to boost their primary exports.

6 This is the typical reductionist approach followed in the empirical literature to test theoretical hypothesis such as, the Feldstein-Horioka puzzle or the Fisher effect. 
Figure 3. Time variation of the medium-term ratio of export/import income elasticities

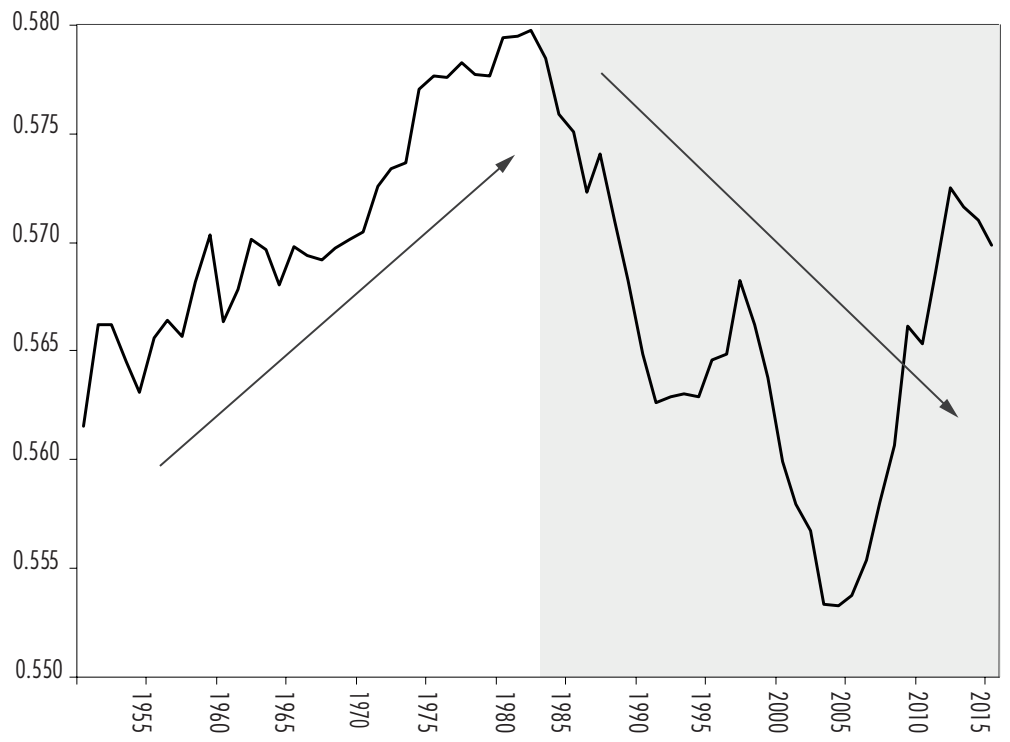

Source: own elaboration.

Overall, these findings imply that the specialization pattern has constrained LA economic growth across the sample since the ratio of elasticities is smaller than unity. This, in turn, indicates that imports income elasticity of demand has been larger than exports income elasticity of demand across both strategies. There is, however, a dramatic difference across regimes; the ratio of elasticities has dropped drastically with economic liberalization compared with ISI, and despite the upswing since 2005, it has remained below the peak it reached under ISI.

Liberal policies have tightened the balance of payments constraint on growth, and LA has moved toward a new low-growth-medium-term equilibrium under neoliberalism due to the specialization pattern the strategy has favored. This may be attributed to the surge of imports that have increased imports elasticity of demand and, at the same time, to a decrease of export elasticity of demand due to a reshape of the productive apparatus according to the Ricardian efficiency. Curiously, even though economic liberalization has succeeded in promoting exports, and in attracting foreign investment, it has shown weaker growth results compared with ISI. This supports the idea that economic growth has a negative correlation with exports growth during liberalization because of the specialization pattern, as suggested by previous literature. 
The upward slope of the ratio of elasticities during ISI is also an exciting finding since it implies the strategy achieved its goal, at least partially, of modifying the specialization pattern in LA. It is widely acknowledged that ISI fostered the production and export of a variety of relatively sophisticated goods. Industrialization enhanced a productive apparatus diversification and promoted a sectorial reaccomodation, which, in turn, contributed to an increase in export elasticity of demand. Nevertheless, it is also well known that import requirements to support industrialization became more complex, and therefore, import elasticity of demand, far from shrinking, continued to increase. Nonetheless, unlike liberalism, ISI placed LA in a clear convergent growth path with Dw.

Following the balance-of-payments-constrained growth literature, this document suggests a new consensus based on aggressive economic and industrial policies to transform the productive apparatus radically and thus overcome this constraint. It is well acknowledged, however, that time has changed, and the expansion of the global value chains, impose bigger challenges than before to any process of industrialization. Nonetheless, LA may draw upon its past and current experiences to create a looking-back-to-look-forward development agenda that defies the prevailing comparative advantages and international division of labor to revamp industry and articulate it at the highest levels of either global or regional value chains.

In the next section, we present an extension of section 2 model where we suggest how systematic investment aimed to modify $\varepsilon_{D W}$ might ignite economic convergence. Although limited in several aspects, the model illustrates how to cope with Ros' criticism of Thirlwall's Law, and how by making $\varepsilon_{D W}$ a decreasing function of $P$, the Paradox breaks down, and investment might sustain a development process.

\section{FROM THIRLWALL'S PARADOX TO STRUCTURAL CHANGE}

Ros (2013) notes that a paradoxical result emerges from the model presented in section 2, which he calls Thirlwall's Paradox. The Paradox states that the economy remains stuck in a trap of falling-behind growth due to the specialization pattern, and efforts to escape are countered by deteriorating terms of trade.

Let us explain the Paradox: Imagine LA strives for increasing its saving rate. According to equation (9) investment increases; therefore, assuming an initial equilibrium condition as described in figure 1 , the $g_{L A}$ line becomes steeper. 
At the initial equilibrium, LA faces a situation where $g_{L A}=\varepsilon_{D W} g_{D W}$; hence, according to equation (10), terms of trade deteriorate over time to restore the balance of payment equilibrium. Deterioration in relative prices discourages capital accumulation, and then the accumulation rate returns to the point where $g_{L A}=\varepsilon_{D W} g_{D W}$ with lower terms of trade compared with the initial equilibrium.

Ros (2013, p. 242) claims that: "Since in this process $\varepsilon_{D W} g_{D W}$ does not change, the new long-run [medium-run in this document] equilibrium will feature lower terms of trade for the home country [LA in this context] and the same rate of accumulation and growth equal to $g_{L A}=\varepsilon_{D W} g_{D W}$ ".

LA can modify $\varepsilon_{D W}$ through a vigorous process of investment aimed to change the productive apparatus to produce high-income-elasticity industrial products. This leads back to Latin American structuralism ideas, as Thirlwall (2002, p. 78) argues: "The only sure and long-term solution to raising a country's growth rate consistent with the balance of payments equilibrium on current account is a structural change to raise $\varepsilon_{D W}$ and to reduce $\varepsilon_{L A}$. We are back to the ideas of Raul Prebisch and the question of the most appropriate industrial policy for countries, and the role of protection".

\section{The long run}

Assume, as usual in dualistic models, that $L=L_{M}+L_{S}$ where $L$ represents the labor force growing at the exogenously given rate $n$. $L$ can be expressed conveniently as $n=\lambda \hat{L}_{M}+(1-\lambda) \hat{L}_{s}$ where $\hat{L}_{s}=\frac{n-\lambda \hat{L}_{M}}{1-\lambda}$ with $\lambda$ as the proportion of the labor force employed in the modern sector $\left(\frac{L_{M}}{L}\right)$. Modern sector's labor growth rate comes from the labor demand found above, thus: $\widehat{L}_{M}=g_{L A^{\prime}}$ Plugging $\hat{L}_{M}$ into $\hat{L}_{s}$ yields,

$$
\widehat{L}_{S}=\frac{1}{1-\lambda}\left[n-\lambda g_{L A}\right]
$$

Hence, the subsistence sector's employment growth rate increases as the population grows and decreases as the modern sector accumulates capital.

As for modern sector labor productivity growth rate $(\xi)$, assume it is a linear function of output growth as suggested by the Kaldor-Verdoorn technical progress function: 


$$
\xi=\gamma_{0}+\gamma_{1} g_{L A}
$$

According to this Kaldor-Verdoorn specification, there exists a two-way causality between economic growth and labor productivity. It is assumed that a higher growth enhances productivity, supports economic advancements, and these, in turn, augment growth (see, e.g., Rada, 2007). In the context of open economies, the virtuous circle between growth and productivity operates through exports, as Kaldor (1981) suggested. In such a case, exports lead to an increase in productivity through the positive relationship they hold with output growth. Thus, substituting (11A) into $\xi$ yields

$$
\xi=\gamma_{0}+\tilde{\gamma}_{1} \varepsilon_{D W}
$$

$$
\text { where } \tilde{\gamma}_{1}=\gamma_{1} g_{D W} \text {. }
$$

Equation (15) captures a critical aspect of economic development according to the Kaldorian perspective on growth: productivity growth is associated with an increasing degree of sophistication of exports. Equation (15) says that productivity increases as the income elasticity of demand for the good produced in LA increases. If the good produced becomes more sophisticated $\left(\varepsilon_{D W}\right.$ rises), production techniques and management capabilities become more sophisticated as well. This, in turn, leads to an expansion in innovation and production, which translates to an increase in productivity according to the Kaldor-Verdoorn theory of technological change.

The chain of events described above supposes the income elasticity of demand is a technological parameter determined by the actual production process rather than determined by consumer preferences. In this sense, $\varepsilon_{D W}$ must be determined by the current technological frontier available for LA. This frontier represents a menu of technological options upon which LA chooses a technique based on its current production process. According to Caselli and Coleman II (2006), developing countries tend to be inside the technology frontier. Thus, $\varepsilon_{D W}$ ought to be determined by the technological gap as measured by the ratio of LA technological capabilities, $\Omega_{L A}$, respect to the technological frontier $\Omega$, that is:

$$
\varepsilon_{D W}=f\left(\Omega_{L A} / \Omega\right)
$$


where $f(\cdot)$ is an increasing function on the technological gap. LA technological capabilities equal the capital stock since capital accumulation and technological progress happens simultaneously. In other words, as LA accumulates capital, it accumulates cutting-edge technology consistent with the current production process backwardness.

By equation (7), capital stock is a decreasing function of the terms of trade. Thus, as long as the absolute value of the elasticity of $K_{M}$ respect to $P$ is larger than $\mu_{D W}, \varepsilon_{D W}$ can be written as a decreasing function on $P$ :

$\varepsilon_{D W}=f\left(\frac{K_{M}(P)}{\Omega}\right)$

Equation (16) suggests that higher terms of trade decrease good's degree of sophistication, i.e., when LA enjoys favorable terms of trade, this reinforces its vocation to export primary goods. Equation (16) is consistent with the findings depicted by figure 3 and with empirical evidence. The tremendous rise in primary terms of trade since 2005 was followed by a significant reprimarization of LA's exports, as Ocampo (2017) shows.

It is now well established in LA development literature that there is a robust premature deindustrialization phenomenon that coincides with the implementation of "getting prices right" policies. In LA, price signals have allocated investment resources in sectors where the region has static comparative advantages that have stagnated others more dynamic such as manufacturing industries. The great tragedy, however, is that the same price mechanism is unable to reallocate resources outside primary sectors without the help of modern industrial policies. In this regard, equation (16) would depict LA deindustrialization as a consequence of price signals.

Finally, (16) implies that equation (11A) can be written as:

$$
g_{L A}=g_{D W} \varepsilon_{D W}(P)
$$

Figure 4 describes the long-term equilibrium based on equations (9), (13), (14), and (17). The equilibrium shows the joint determination of the terms of trade, and the growth rates of output, labor productivity, and employment. Similarly to Rada (2007), quadrant II shows the employment growth contours along which $\hat{L}_{S}$ is constant $\left(\overline{\hat{L}}_{S}\right)$. As the output equilibrium point shifts upwards in quadrant I, employment in the subsistence sector shrinks. While the lower plateau-shaped portion of (17) stands for the minimum rate of growth granted by the specialization pattern, the upper plateau-shaped 
Figure 4. Long-term equilibrium

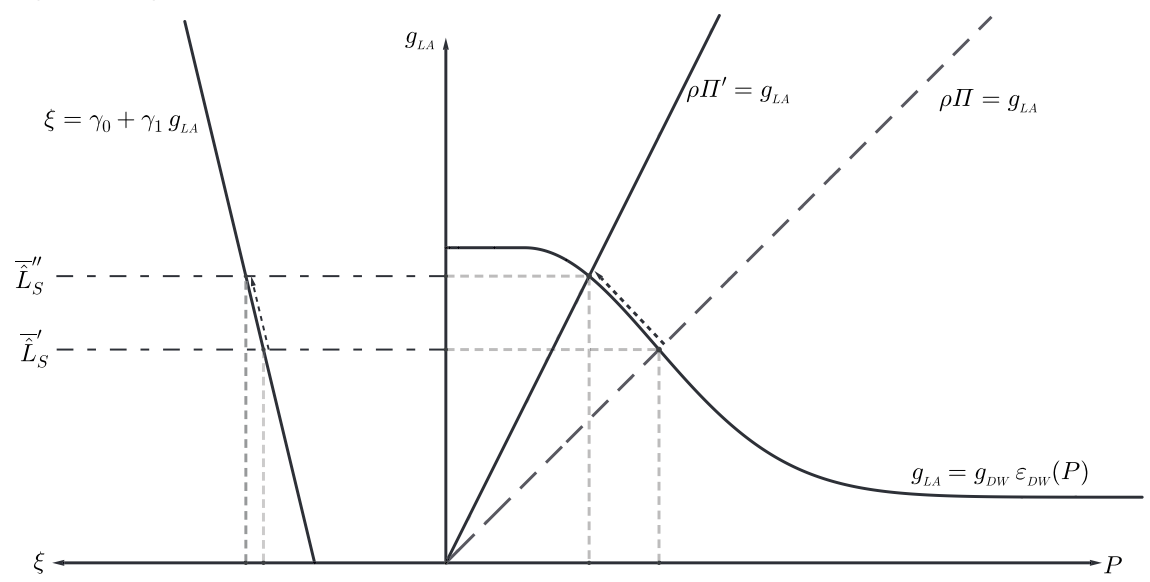

Source: own elaboration.

portion represents the limit to convergence that can result from changes in the specialization pattern.

Let us analyze the equilibrium conditions. Imagine LA increases investment, then $g_{L A}$ line becomes steeper. This immediately triggers a deterioration of the terms of trade as Thirlwall's Paradox states. Lower terms of trade increase the export income elasticity of demand, which generates a higher output and higher labor productivity, as Kaldor-Verdoorn theory of technological change suggests. Modern sector enlargement draws workers from the subsistence sector, and thus LA starts a long journey toward convergence with DW through systematic changes in $\varepsilon_{D W}$.

It is noteworthy to mention, however, that the convergence path suggested by the model does not change LA's dependent development trait. Growth determinants continue to be the ratio of elasticities and Dw's growth rate. Also, the investment good continues to be produced by developed countries. Hence, under the structural transformation process suggested here, there is no creation of new technology by LA, but a process of acquisition, mastery, and adaptation of current advanced technology and techniques produced in developed countries. Further studies might investigate how to modify the model's dependent development feature by including the capital stock along with the specialization pattern as a determinant of growth.

Certainly, development is not a smooth process, as depicted above. It will require modern government policies to reverse the asymmetric behavior of the allocation of investment resources and deindustrialization caused by 
price signals. The specialization pattern has primarily been responsible for the economic malaise that has taken hold since the economic liberalization, and therefore, government policies turn indispensable since, under current conditions, structural change is a costly decision.

\section{FINAL REMARKS}

In this document, we apply Thirlwall's Law to determine the severity of the specialization pattern constraint on LA's economic growth over the period 1950-2016. Using cointegration that allows for a structural break and timevarying parameter techniques, we show that specialization pattern has constrained economic growth in LA. Results, however, suggest that the constraint has tightened under economic liberalization due to the static comparative advantage that the strategy promotes. Even though IsI's main aim of a radical transformation of the specialization pattern was partially achieved, industrialization generated a catch-up growth process in LA, despite its inefficiencies.

Economic liberalization, which has proved costly regarding growth, has promoted a specialization pattern -strongly biased in favor of primary export industries- that has moved LA economy into a low-growth equilibrium. Apparently, this low development trap may be the reason why structuralism fought against any complete specialization of LA in primary production. In this document, we suggest, based on the findings, that LA must reconsider its development agenda to start a search of the dynamic efficiency to upgrade its productive apparatus based on more dynamic sectors. Concretely, LA must ignite a structural change program to converge with developed economies in economic structure and, thus, to close the income gap with the more advanced countries.

\section{REFERENCES}

Akamatsu, K. (1962), "A historical pattern of economic growth in developing countries", Developing Economies, vol. 1, num. 1, DOI <10.1111/j.17461049.1962.tb01020.x>

Bhargava, A. (1986), "On the theory of testing for unit roots in observed time series", Review of Economic Studies, 53, DOI < 10.2307/2297634>

Carrion-i-Silvestre, J. and Sansó, A. (2006), "Testing the null of cointegration with structural breaks", Oxford Bulletin of Economics and Statistics, vol. 68, num. 5, DOI <10.1111/j.1468-0084.2006.00180.x> 
Caselli, F. and Coleman II, W. (2006), "The world technology frontier”, American Economic Review, vol. 96, num. 3, DOI <10.1257/aer.96.3.499>

Chami, J. (2004), "Latin American export specialization in resource-based products: Implications for growth", Developing Economies, vol. 42, num. 3, DOI <10.1111/j.1746-1049.2004.tb00942.x>

Cimoli, M., Porcile, G. and Rovira, S. (2010), "Structural change and the BOp-constraint: why did Latin America fail to converge?”, Cambridge Journal of Economics, vol. 34, DOI <10.1093/cje/ben060v>

Cimoli, M. and Porcile, G. (2014), “Technology, structural change and вopconstrained growth: A structuralist toolbox", Cambridge Journal of Economics, vol. 38, DoI $<10.1093 /$ cje/bet020>

Clavijo, P. and Ros, J. (2015), "La Ley de Thirlwall: una lectura crítica", Investigación Económica, vol. 74, num. 292, DOI <10.1016/j.inveco.2015.08.001>

Dutt, A. (2002), "Thirlwall's Law and uneven development", Journal of Post Keynesian Economics, vol. 24, num. 3, DOI <10.1080/01603477.2002.11 490331>

Elder, J. and Kennedy, P. (2001), "Testing for unit roots: What should students be taught?", The Journal of Economic Education, vol. 32, num. 2, DOI $<10.1080 / 00220480109595179>$

Elliott, G., Rothenberg, T. J. and Stock, J. H. (1996), "Efficient tests for an autoregressive unit root", Econometrica, vol. 64, DOI <10.2307/2171846>

Ferreira, L. and De Santana, L. (2019), "Economic growth and manufacturing: An analysis using Panel var and intersectoral linkages", Structural Change and Economic Dynamics, vol. 49, DOI <10.1016/j.strueco.2019.03.008>

Geronimi, V. and Taranco, A. (2018), "Revisiting the Prebisch-Singer hypothesis of a secular decline in the terms of trade of primary commodities (1900-2016). A dynamic regime approach", Resources Policy, vol. 59, DOI $<10.1016 /$ j.resourpol.2018.08.005>

Gregory, A., Nason, J. and Watt, D. (1996), "Testing for structural breaks in cointegrated relationships", Journal of Econometrics, vol. 71, num. 1-2, DOI $<10.1016 / 0304-4076(96) 84508-8>$

Guerrero, C. (2006), "Thirwall's Law with an emphasis on the ratio of exports/imports income elasticities in Latin American economies during the twentieth century", Estudios Económicos, vol. 21, num. 1, DOI <10.24201/ ee.v21i1.159>

Hausmann, R., Hwang, J. and Rodrik, D. (2007), "What you export matters", Journal of Economic Growth, vol. 12, num. 1, DOI <10.1007/s10887006-9009-4> 
Ibarra, C. (2015), “Comentario a 'La Ley de Thirlwall: una lectura crítica' de Pedro Clavijo y Jaime Ros”, Investigación Económica, vol. 74, num. 292, DOI $<10.1016 /$ j.inveco.2015.08.002>

Inklaar, R., De Jong, H., Bolt, J. and van Zanden, J. (2018), Rebasing "Maddison": new income comparisons and the shape of long-run economic development. GGDC Research Memorandum, vol. GD174, Groningen, Groningen Growth and Development Center.

Kaldor, N. (1981), "The role of increasing returns, technical progress and cumulative causation in the theory of international trade", Economie Appliquée, an International Journal of Economic Analysis-Paris: ISMEA, ISSN 0013-0494, ZDB-ID 216115-1, vol. 24, num. 4.

Kreinovich, V. and Sriboonchitta, S. (2019), Structural changes and their econometric modeling, Springer.

Lee, J. and Strazicich, M. (2013), "Minimum LM unit root test with one structural break", Economics Bulletin, vol. 33, num. 4.

$\mathrm{Ng}$, S. and Perron, P. (2001), "LAG length selection and the construction of unit root tests with good size and power", Econometrica, vol. 69, num. 6, DOI $<10.1111 / 1468-0262.00256>$

Ocampo, J. A. (2017), "Commodity-Led development in Latin America", International Development Policy, vol. 9, DOI <10.4000/poldev.2354>

Pacheco-López, P. and Thirlwall, A. (2006), "Trade liberalization, the income elasticity of demand for imports, and growth in Latin America", Journal of Post Keynesian Economics, vol. 29, num. 1, DOI <10.2753/PKE01603477290103>

Pérez, E. (2015), “Una lectura crítica de 'la lectura crítica' de la Ley de Thirlwall”, Investigación Económica, vol. 74, num. 292, DOI <10.1016/j. inveco.2015.08.003>

Perron, P. (1989), "The great crash, the oil price shock, and the unit root hypothesis", Econometrica, vol. 57, num. 6, The Econometric Society.

Perrotini, I. and Vázquez, J. (2019), "Endogenous growth, capital accumulation and Thirlwall's dynamics: The case of Latin America", Review of Keynesian Economics, vol. 7, num. 4, DOI <10.4337/roke.2019.04.03>

Phillips, P. C. B. (1987), “Time series regression with unit roots”, Econometrica, vol. 55, num. 2, The Econometric Society.

Phillips, P. C. B. and Perron, P. (1988), "Testing for a unit root in time series regression", Biometrika, vol. 75, num. 2, Oxford University Press.

Prebisch, R. (1950), The economic development of Latin America and its principal problems, New York, ECLAC. 
Rada, C. (2007), "Stagnation or transformation of a dual economy through endogenous productivity growth", Cambridge Journal of Economics, vol. 31, num. 5, DOI <10.1093/cje/bem004>

Razmi, A. (2016), "Correctly analysing the balance-of-payments constraint on growth", Cambridge Journal of Economics, vol. 40, num. 6, DOI <10.1093/ cje/bev069>

Ros, J. (2001), "Industrial policy, comparative advantages and growth", CEPAL Review, vol. 73, April.

(2012), "Latin America's trade and growth patterns, the China factor, and Prebisch's nightmare", Journal of Globalization and Development, vol. 3, num. 2, DOI <10.1515/jgd-2012-0031>

(2013), Rethinking economic development, growth, and institutions, Oxford, oup.

Ros, J. and Clavijo, P. (2015), "Respuesta a Ibarra, Pérez y Vernengo", Investigación Económica, vol. 74, num. 292, DOI <10.1016/j.inveco.2015.05.004>

Sachs, J. and Warner, A. (1997), Natural resource abundance and economic growth, Cambridge, Harvard Institute for International Development. and Warner, A. (1999), "The big push, natural resource booms and growth", Journal of Development Economics, vol. 59, num. 1, DOI <10.1016/ S0304-3878(99)00005-X>

Sala-i-Martin, X. (1997), "I just ran two million regressions", American Economic Review, vol. 87, num. 2, May, American Economic Association.

Sasaki, H. (2008), "North-South Ricardian trade and growth under the balance-of-payments constraint", Journal of Post Keynesian Economics, vol. 31, num. 2, DOI <10.2753/PKE0160-3477310206>

Taylor, L. (1983), Structuralist macroeconomics: Applicable models for the third world, New York, Basic Books.

Thirlwall, A. (1979), "The balance of payments constraint as an explanation of international growth rate differences", Banca Nazionale del Lavoro Quarterly Review, vol. 32, num. 128.

(2002), The nature of economic growth, United Kingdom, Edward Elgar.

Vera, L. (2006), "The balance-of-payments-constrained growth model: A north-south approach", Journal of Post Keynesian Economics, vol. 29, num. 1 , DOI <10.2753/PKE0160-3477290104>

Vernengo, M. (2015), "Una lectura crítica de la crítica al modelo de Thirlwall”, Investigación Económica, vol. 74, num. 292, DOI <10.1016/j. inveco.2015.05.003> 